NASA Technical Memorandum 102863

\title{
Cryo-Mechanical Tests of Ames 24E2 IR-Black Coating
}

\section{Sheldon M. Smith}

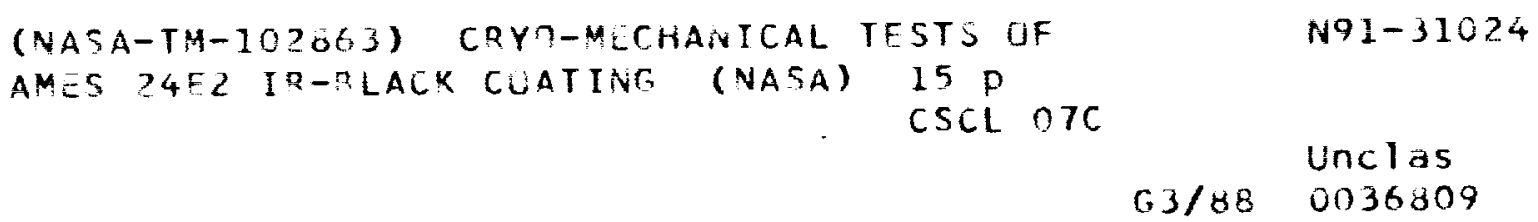

June 1991

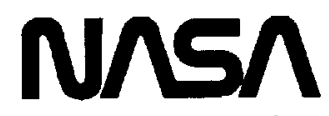

National Aeronautics and

Space Administration 
$-+$

$\bar{\vdots}$ 
NASA Technical Memorandum 102863

\section{Cryo-Mechanical Tests of Ames 24E2 IR-Black Coating}

Sheldon M. Smith, Ames Research Center, Moffett Field, California

June 1991

\section{N/SA}

National Aeronautics and

Space Administration 
.

,

.

.

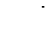




\section{SUMMARY}

In addition to the ambient condition "tape test," five mechanical tests of the IR-black coating, Ames 24E2, have been performed at either liquid helium or liquid nitrogen temperature. Tensile strain in the coating at liquid nitrogen temperature has been measured up to values of $4 \mathrm{E}-3$, both before and after the coating was cycled down to liquid helium temperature. When applied to an aluminum substrate which was then bent in liquid nitrogen, the aluminum substrate always failed (permanently deformed) well before the coating failed. Sinusoidal accelerations up to $45 \mathrm{Gs}$ in liquid nitrogen and $25 \mathrm{Gs}$ in liquid helium did not crack or otherwise visibly damage the coating. Both sinusoidal and random acceleration at about $90^{\circ} \mathrm{K}$ of a representative baffle vane structure, at frequencies from 10 to $2,000 \mathrm{~Hz}$ and up to $15 \mathrm{Gs}$, did not damage the coating, even at the intersection of a baffle with the telescope tube. Thus on a macroscopic level, cryogenic cooling and various levels of acceleration and strain did not affect this coating. However, on a microscopic scale some loose particles were found associated with several tests. Since they were also noted during room temperature trials, it is concluded that a few weakly bound particles probably exist on the coating surface immediately after application. A lower bound of about 30 large, and 75 small, particles per square meter is established. Outgassing data are also given.

\section{INTRODUCTION}

Ames 24E2 is an infrared-black coating designed to reduce stray light inside far-infrared telescopes such as SIRTF, COBE, and ISO. These cryogenically cooled telescopes and the coatings used within them must be able to withstand severe launch vibration at cryogenic temperatures. This paper presents the results of tests performed to evaluate the mechanical characteristics of the coating, especially at cryogenic temperatures. Its outgassing properties are described as well. The infrared reflectance characteristics of this coating have been reported in an earlier paper (ref. 1).

Several properties of Ames 24E2 are more easily understood when its components are known. The basic binder is ECP-2200, which will soon be produced by IITRI in Chicago, IL. To that are added silicone adhesive resin and carbon black powder. The final component is \#80 SiC grinding grit. The objective of this formulation is to make a rough, thick, absorbing coating. Its exact formulation is given in reference 2 .

The author is indebted to Mr. W. A. Campbell of Goddard Space Flight Center for his advice and assistance; and to Mr. Jamie Brock of UC Berkeley for designing the representative baffle assembly described in Section 4.4 and for assisting with the cryo-vibration tests.

\section{OUTGASSING}

Outgassing tests were performed by W. A. Campbell at the Goddard Space Flight Center in accordance with ASTM Test Method E-595-84 and as described in NASA Reference 
Publication 1124 Revised (ref. 3). Free-standing samples of the coating were radiatively baked at $135^{\circ} \mathrm{C}$ between two quartz lamps for $24 \mathrm{hr}$ under mild vacuum before testing. The results are shown in table 1 , where $\mathrm{TML}=$ total mass loss, $\mathrm{WVR}=$ water vapor regain, and $\mathrm{CVCM}=$ collected volatile condensible material.

Table 1. Outgassing data for Ames 24E2

\begin{tabular}{ccc}
\hline \hline \%TML & \%WVR & \%CVCM \\
\hline 0.31 & 0.22 & 0.00 \\
\hline \hline
\end{tabular}

It should be emphasized that radiative baking at higher temperature $\left(280^{\circ} \mathrm{C}\right)$ and for a longer duration $(48 \mathrm{hr}$ ) did not change these data by a significant amount. However, conductive baking on a hot-plate of an early sample (ref. 3) (1987) did not produce nearly as clean results. Radiative curing of this coating is clearly the technique of choice. These results easily meet the $1 \%$ TML and $0.1 \%$ CVCM acceptable maximums given in ASTM E-595-84.

\section{AMBIENT TEMPERATURE TESTS}

\section{1 "Tape Test," ASTM Standard Test Method D-3359}

The Ames 24E2 coating passed this somewhat subjective adhesion test with a score of about 4.5 on a scale of 0 to 5 , where 5 indicates "no peeling or removal." Four samples of two coats each on aluminum substrates were tested under ambient conditions. The only peeling or removal of the coating observed was quite small, and it occurred at the narrow angle intersection of the two knife cuts into the coating which are part of the test. At a few locations along the cuts the knife blade dislodged a SiC grit which left a pinhole in the coating. This result was not part of the test, but it is not surprising considering the construction of the coating.

\subsection{Handling Fragility}

Historically, optical black coatings such as $3 \mathrm{M}$ Black Velvet and Martin Black have not been intended for high wear or abrasive applications because such use breaks off the facets that create the roughness of the coating surface. Nor is Ames 24E2 intended for use in a high wear application; therefore, tests such as the Taber Abraser, scrape adhesion, or the Pfund Hardness Test are not appropriate. Experience using the coating inside cryogenically cooled instruments and detectors at Ames Research Center and other laboratories indicates that the coating basically adheres to aluminum and copper quite well, as indicated on the Tape Test. However, instrument parts which are continually handled, such as focusing knobs or alignment screws, have been found to produce some loose black particles. The amounts were small and not quantified. Since $\mathrm{SiC}$ grit is a major component of the coating, this is not particularly surprising. It could be easily remedied by not coating such 
parts until after the adjustments were completed. However, this experience does indicate a potential adhesion problem, and some test of handling fragility would seem useful. Two simple tests were devised.

3.2.1 Acid Brush Test- Soft, but moderately stiff brushes of bristle or horsetail hair are commonly used for applying acid to metal joints in preparation for soldering. Hence the name "acid brush." These little brushes are about $3 / 8$ in. wide by $3 / 4$ in. long, and are stiff enough to move large particles, but still soft enough not to scratch most surfaces. For example, they do not visibly scratch or otherwise mar the surface of Chemglaze Z-306, Floquil, or 3M Black Velvet coatings. But they do visibly damage the very fragile anodized surface of Martin Black and Infrablack. Because of their intermediate stiffness, these brushes were selected to evaluate the surface integrity of Ames 24E2. After the coating had dried, the surface was brushed downward with moderate pressure above a clean sheet of white paper. The number of grit or other black particles appearing on the paper from a measured area of brushed coating was counted and reported as the number of weakly bound particles/square meter. From four samples of Ames 24E2, this test generated an average of 220 large $(250-450 \mu \mathrm{m})$ particles/sq. meter. Surprisingly, a bi-modal size distribution was discovered. Using a $50 \mathrm{x}$ microscope, an even larger number of small particles in the 30-125 $\mu \mathrm{m}$ size range was counted. Under a stainless steel probe at $100 \mathrm{x}$, it was found that the smaller particles were soft, sticky, and had a translucent interior even though they were black on the outside. Thus it is probable that they are composed of carbon-black pigmented adhesive resin. The larger particles are undoubtedly black pigmented paint and resin covering the $\# 80 \mathrm{SiC}$ grit, because the modal size of $\# 80$ grit $^{4}$ is about $300 \mu \mathrm{m}$. Also, shiny grey facets are occasionally seen on the large particles. The result for a few other black coatings is compared in table 2 . In performing this test, care must be taken that the coated/brushed area does not extend to the edge of the substrate because edge adhesion is not as strong as surface adhesion.

Table 2. Acid brush test

\begin{tabular}{|c|c|c|c|c|c|}
\hline \multirow[b]{2}{*}{ Coating } & \multirow[b]{2}{*}{$\begin{array}{l}\text { Visible } \\
\text { damage }\end{array}$} & \multirow{2}{*}{\multicolumn{2}{|c|}{$\begin{array}{c}\text { Area } \\
\text { brushed }\end{array}$}} & \multicolumn{2}{|c|}{ Weakly bound particles per sq. $\mathrm{m}$. } \\
\hline & & & & $\begin{array}{c}\text { Large } \\
(250-450 \mu \mathrm{m})\end{array}$ & $\begin{array}{c}\text { Small } \\
\text { (see below) }\end{array}$ \\
\hline Ames 24E2 & None & 184 & sq. cm. & 220 & $(30-125 \mu \mathrm{m})$ \\
\hline 3M Black Velvet & None & 100 & sq. $\mathrm{cm}$. & 0 & $3.1 \mathrm{E}+3(12-60 \mu \mathrm{m})$ \\
\hline Chemglaze Z-306 & None & 6.5 & sq. $\mathrm{cm}$. & 0 & 0 \\
\hline Martin Black & Yes & 6.5 & sq. cm. & 0 & $3.2 \mathrm{E}+5(20-40 \mu \mathrm{m})$ \\
\hline
\end{tabular}

3.2.2 Finger Rub Test- This mild abrasion test simply consists of five hard rubs of the index finger across the surface of the coating above a clean sheet of white paper. The number of particles dislodged per square meter and the visible damage are reported. The results from three samples of Ames 24E2 are shown in table 3 . The slight visible damage to the coating consisted of skin particles stuck onto it. It is not surprising that 15 times as many particles were dislodged from A24E2 in this 
Table 3. Finger rub test

\begin{tabular}{lllllll}
\hline \hline \multicolumn{1}{c}{ Coating } & \multicolumn{1}{c}{$\begin{array}{c}\text { Visible } \\
\text { damage }\end{array}$} & $\begin{array}{c}\text { Area } \\
\text { rubbed }\end{array}$ & $\begin{array}{c}\text { Particles dislodged per sq. m. } \\
\text { Large } \\
(250-450 \mu \mathrm{m})\end{array}$ & $\begin{array}{c}\text { Small } \\
\text { (see below) }\end{array}$ \\
\hline Ames 24E2 & Slight & 135 & sq. cm & $3.2 \mathrm{E}+3$ & $3.0 \mathrm{E}+3$ & $(30-125 \mu \mathrm{m})$ \\
3M Black Velvet & None & 100 & sq. cm. & 0 & $2.1 \mathrm{E}+3$ & $(12-60 \mu \mathrm{m})$ \\
Chemglaze Z-306 & None & 6.5 & sq. cm. & 0 & 0 & \\
Martin Black & Yes & 6.5 & sq. cm. & 0 & $1.7 \mathrm{E}+5$ & $(20-40 \mu \mathrm{m})$ \\
\hline \hline
\end{tabular}

test as during the Acid Brush Test. The small decrease noted in 3M Black Velvet and Martin Black particles probably occurred because the same sample had been used in the Acid Brush Test as well.

\section{CRYOGENIC TEMPERATURE TESTS}

\subsection{Tensile Strain Test}

When a coated substrate is bent, the coating experiences compressive or tensile strains equal to that at the surface of the substrate. This is true until the shear force associated with the strain exceeds the adhesive force binding the coating to the substrate, at which point the coating "fails" and no longer follows the bend of the substrate. Usually the coating separates from the substrate in some manner after failing. At cryogenic temperatures many organic materials become rigid and brittle, hence it is quite possible that a coating will fail at a considerably lower level of strain when cold than when warm. A cryogenic strain test apparatus was designed to investigate this possibility.

The tensile strain $E(x, d)$ at the upper surface of a cantilever beam at point $x$ when the free end of the beam is depressed a distance $\mathrm{d}$ has been derived by C. C. Hiel (personal communication) of the Test Engineering Branch at Ames Research Center. It is given by

$$
\mathrm{E}(\mathrm{x}, \mathrm{d})=\Delta \ell / \ell=\frac{1.5 \mathrm{dhx}}{\ell^{3}}
$$

where the dimensions $\mathrm{h}$ and $\ell$ are shown in figure 1. It is interesting to note that the strain, a unitless quantity by definition, is independent of the elastic modulus of the beam material and increases linearly with the distance $x$ from the free end. In principle, the point of failure of a coating under strain will be indicated in some visible manner and thus define the value of $\mathrm{x}$ at failure.

Equation (1) was calibrated electrically by mounting strain gauges on each side of a beam (at $\mathrm{x}=3.90 \mathrm{in}$., with $\mathrm{l}=5.15$ in.) and attaching them to a Wheatstone bridge circuit. Because the electrical resistance of a wire is proportional to its length, the voltage measured across a bridge circuit with 
strain gauges in two of its arms can be related to the mechanical strain through a known gauge calibration factor, $G_{f}$.

$$
E(d)=\frac{2 V(d)}{e_{i} G_{f}}
$$

In equation (2), $e_{i}$ is the bridge supply voltage and $V(d)$ is the voltage across the bridge with the beam depressed a distance $d$. It should be noted that $G_{f}$ was determined by the gauge manufacturer at a temperature of $75^{\circ} \mathrm{C}$. Equations (1) and (2) apparently give the same result. They were applied to two different thickness beams of 2024-T3 aluminum at room temperature by measuring the voltage $\mathrm{V}$ as a function of deflection $\mathrm{d}$. Values of the strain calculated from equation (1) were found to differ from those obtained from equation (2) by only $-0.7 \%$ for a 0.062 in. thick beam and by $+5 \%$ for a beam 0.091 in. thick, thus confirming the accuracy of the mechanical theory. By means of equation (1), the calibration was extended to beam thicknesses of $0.032 \mathrm{in}$. and $0.126 \mathrm{in}$. with an uncertainty of only $\pm 2.6 \%$.

Because equation (1) is independent of the elastic modulus of the material, the strain at the surface of the beam does not depend upon temperature. However, the resistance of the wire in the strain gauge and the adhesion of the epoxy binding it to the aluminum beam are temperature dependent, hence a cold calibration of equation (1) was not expected to be successful. However, because the strain apparatus was designed to operate under liquid nitrogen, it was easy to test. The strain measurements of $\mathrm{V}$ as a function of $\mathrm{d}$ were repeated with the beam completely submerged in liquid nitrogen. The gauges did not de-bond, and the readings were consistently $7 \%$ and $8 \%$ below the warm electrical data for the two different thickness beams. This consistent difference is attributed to a thermal change of the strain gauge factor $\left(G_{f}\right)$ from its warm value.

Following the above calibrations, six samples of Ames 24E2 approximately $600 \mu \mathrm{m}$ thick and $21 \mathrm{~cm}^{2}$ in area were prepared for cold strain testing by a $150^{\circ} \mathrm{C}$ bake-out for $24 \mathrm{hr}$ under mild vacuum. These samples had been coated on 2024-T3 aluminum beams that were $15 \mathrm{~mm}$ wide, $131 \mathrm{~mm}$ long, and $0.81,1.55$, and $2.31 \mathrm{~mm}$ thick. Each coated beam was individually immersed in liquid nitrogen and the free end depressed the distance necessary to create : calibrated strain of 3.15 E-3. This deflection was repeated 10 times while the coating was studied visually through the liquid nitrogen to determine where along the beam the coating first failed. No coating detachment or other failure was observed. The deflection of the beam was then increased in $1.3 \mathrm{~mm}$ increments until the aluminum substrate itself failed (was permanently bent), which occurred at a strain of approximately 4 E-3. Still no coating failure occurred. Several of the coated beams were bent well beyond their first point of permanent deformation, also without any coating detachment or other failure. It was finally concluded that Ames 24E2 could sustain cold static strains in excess of 4 E-3 and that further strain tests were unnecessary as the aluminum substrate itself would fail before the coating would.

\subsection{Thermal Cycling Test}

Because it is anticipated that the SIRTF telescope may be cooled down to liquid helium temperature several times before launch, five samples of Ames $24 \mathrm{E} 2$ coating were thermally cycled six times 
each from above $315^{\circ} \mathrm{K}$ down to about $4^{\circ} \mathrm{K}$ and back up again. The thermal cycling was carried out by heating the sample directly with a $20 \mathrm{KW}$ heat-gun to above $315^{\circ} \mathrm{K}$, briefly cooling it with a fan, and then immersing it directly in liquid helium. In an effort to evaluate whether the thermal cycling affected the adhesion of the coating, the samples were first bent in liquid nitrogen to a calibrated strain of $3.15 \mathrm{E}-3( \pm 2.6 \%)$, then cycled down to $4^{\circ} \mathrm{K}$ and back up again 6 times, and then deflected again to a strain of $3.15 \mathrm{E}-3$. All five samples withstood this drastic thermal cycling procedure without demonstrating any decrease in adhesion or failure of any other macroscopic mechanical property. One sample was bent well beyond a strain of $4 \mathrm{E}-3$ without failing, although its aluminum substrate was permanently deformed. During these harsh tests no flaking or peeling of the coating were detected, however a few black particles with about 250 - $400 \mu \mathrm{m}$ dimensions were recovered from the container used to immerse the coating samples in the liquid helium.

\subsection{Simple Cryogenic Acceleration Tests}

The launch of a space vehicle subjects the vehicle and its contents to a wide range of accelerations over a broad frequency band. Simple sinusoidal acceleration over an even broader range was used at cryogenic temperatures to test the adhesion of the coating under simulated cold launch conditions. These tests were performed first in liquid nitrogen, and later in liquid helium, by vibrating coated coupons directly in the liquid. The friction of the liquid moving over the surface of the coating may have made these tests slightly more severe than the actual cold launch situation.

Cylindrical rods of 2024-T3 aluminum were coated with two coats of Ames 24E2 and baked at $150^{\circ} \mathrm{C}$ for $24 \mathrm{hr}$ before testing. The coated rods were attached to an audio speaker coil whose frequency was swept across the specified range by a function generator. An accelerometer mounted on the test rod above the level of the liquid cryogen measured the sinusoidal acceleration of each sample. This arrangement was used to drive the samples in liquid nitrogen from 60 to $500 \mathrm{~Hz}$ at about $45 \pm 5 \mathrm{G}$ 's, and in liquid helium from 70 to $500 \mathrm{~Hz}$ at about $25 \pm 5 \mathrm{G}$ 's. Sinusoidal vibration at $20 \mathrm{~Hz}$ was also performed at $8 \mathrm{G}$ 's. Two samples, each of $22 \mathrm{~cm}^{2}$ area, were run in liquid nitrogen for a total of seven minutes. Two other samples, each of $26 \mathrm{~cm}^{2}$ area, were vibrated in liquid helium for a total of 30 minutes.

The samples were examined visually both before and after these cold vibration runs. No difference from the pre-test examination was found on any sample. The liquid nitrogen runs were performed in a strip-silvered dewar flask where the samples could be seen visually. No flaking, shedding, or fracturing of the coating was observed. Thus, these cryogenic vibration tests did not produce any macroscopic, visible, change in the coating. However, a few black particles were collected in the cup that enclosed the coatings tested in liquid helium (but none in the liquid nitrogen flask). A similar number of black particles were also found in the cup following these vibration tests at room temperature. The presence of these few particles is disconcerting, but it would appear that they are not associated with the temperature of the tests. 


\subsection{Cryogenic Vibration of a Representative Baffle Vane Assembly}

Since small samples of the coating appeared to withstand the cryogenic strain and acceleration tests described in the previous paragraphs, the next phase of testing was to cryogenically vibrate a representative baffle vane structure. Because the coating did not macroscopically come off the previous substrate coupons but some small particles were found, a microscopic particle contamination experiment was designed. A representative baffle vane assembly was provided by Andrew Lange's group at the University of California, Berkeley. They had a $10 \mathrm{~cm}$ diameter, liquid helium cooled far-infrared telescope being prepared for a sounding rocket launch from Nagoya, Japan, and they desired to test an epoxy based coating of their own design. The assembly, shown in figure 2 being mounted in a nitrogen-cooled adaptor, consisted of a single $10 \mathrm{~cm}$ ID aluminum vane bolted inside a $13 \mathrm{~cm}$ diameter telescope tube. It had a coated area of $335 \mathrm{~cm}^{2}$.

After two coats of Ames 24E2 had been applied to the baffle vane assembly it was baked at $150^{\circ} \mathrm{C}$ under mild vacuum for $24 \mathrm{hr}$. In this application the sharp inside edge of the baffle vane was fully coated, but a $1 \mathrm{~mm}$ wide band on each side of the intersection of the outer edge of the vane with the telescope tube was left uncoated. In this way if the vane were to come loose and vibrate along the inside of the tube, no paint would be scraped off. Visual inspection of the baffle vane showed large paint particles protruding from the inside edge before the vibration test. The coated and baked baffle assembly was mounted inside a special liquid nitrogen cooled adaptor, which itself was then mounted on top of a Ling Model A300B Vibration System. The vibration direction was vertical and parallel to the axis of the telescope tube, hence perpendicular to the plane of the baffle vane. Directly below the baffle assembly a $15 \mathrm{~cm}$ diameter pyrex petri dish was held in place with a specially cushioned teflon ring. Anything shaken off the baffle assembly had to fall into this collection dish.

Thermocouples mounted on the flange holding the baffle vane assembly in place monitored its temperature while liquid nitrogen flowed through channels in the adaptor plate. An accelerometer mounted on the vibration table measured the acceleration imparted to the apparatus. The vibration spectrum of regular sinusoidal oscillations shown in figure 3 was selected by the Berkeley group as being appropriate for their purpose. The random mode vibration spectrum shown in figure 4 was specified by Li S. Chang for the SIRTF telescope in Ames Technical Note SRT-TN-LSC 310789.

Before the coating was tested, three calibration runs of an uncoated assembly were performed to evaluate the cleanliness of the system and to determine the level of background particle contamination. It was found necessary to follow standard clean room procedures in order to reduce the background particle level. Following each run the nitrogen-cooled adaptor was opened in a special, access controlled, room and the petri collection dish immediately covered; then it was removed from the adaptor for optical scanning. The glass-covered collection dish containing the shake-out from each vibration run was scanned on a Nikon Epiphot-TME inverted microscope at 100 power with dark-field illumination. Some 65 separate scans were required to completely cover one dish at this magnification. Under dark-field illumination, every non-black object on the microscope stage scattered a great deal of light directly into the microscope objective and could be clearly discriminated from a dark coating particle on the basis of brightness and color. Lint, dust, glass beads, traces of tape, and small metal filings appeared bright, colored or translucent, and/or shiny. When a dark, opaque object was found all ambient background illumination was blocked with a dark card, and the microscope illumination varied from "off" to full "on." Under this varying dark-field illumination, particles of Ames 24E2 were not visible at low illumination and were further characterized by being 
the last object in the field of view to brighten at high illumination. Background contamination particles were found to be generally quite small $(<40 \mu \mathrm{m})$ with a dark, grey-black appearance and a characteristic size distribution that increased toward smaller particle sizes, as shown in figure 5 . In this figure the average particle count from runs \#1 and \#5 is shown before the average background count was removed. Particles of Ames 24E2 had a bi-modal size distribution, as discovered earlier on the Acid Brush Test. Particles in the large size mode had at least one dimension $>200 \mu \mathrm{m}$ and a characteristic coal-black color that became somewhat like gun-metal blue at the highest illumination. They sometimes appeared to have a somewhat bubbly surface texture or shiny crystal-like facets. Particles in the smaller size mode, which was centered at $45 \mu \mathrm{m}$, had the same characteristic coal-black color and texture. One of them is shown in figure 6 at 100 power magnification (the larger coating particles were outside the depth of focus of the microscope when it was used as a camera.) The Epiphot microscope contained an Austenite reticle which was used to evaluate particle size according to ASTM Standard Practice E-112.

The first, coated and baked, baffle vane assembly was subjected to four cold vibration runs. The temperature on these runs was $90^{\circ} \mathrm{K} \pm$ about $5^{\circ} \mathrm{K}$. The first two runs (\#173 and 174) were simply the initial run and a repeat. Prior to the third run (\#176), the $1 \mathrm{~mm}$ gap in the coating at the vane-tube intersection mentioned earlier was coated with two coats of Ames 24E2 and baked for $24 \mathrm{hr}$. The fourth run was essentially a repeat of the third run, except that the random vibration mode in figure 4 was used. For the fifth run (\#180) a new, clean, baffle vane assembly was given two coats of Ames $24 \mathrm{E} 2$ and the usual $24-\mathrm{hr}$ bake at $150^{\circ} \mathrm{C}$. On this assembly, the vane-tube intersection was completely coated from the start. However, the sharp inner edge of the baffle vane was given special treatment. It was noted earlier that some large particles of the coating protruded from this edge prior to the first run. When that happens, a smaller fraction of the particle surface is used to bind it to the baffle vane than for particles located entirely on the vane's surface. To eliminate these less firmly attached edge particles, the inner edge of the baffle vane was coated with a version of Ames 24E2 which had been filtered through a paint strainer to remove the large particles. This grit-free formulation is labeled Ames 24E2M.

\subsection{Results of Cryo-Vibration}

The results of the five cryogenic vibration runs of the baffle vane assemblies are shown in table 4 . The background contamination count, which was determined on the initial calibration runs, has been subtracted out of this data. As a preface to the discussion of these results, it should be stated that the coating did not fail in a macroscopic manner as a result of any of these runs. Only microscopic examination of the glass collection dishes showed evidence of fall-out from the cryogenic vibration. Several points may be deduced from table 4 and figure 5 .

1. Both microscopic and physical examination of the particles themselves, and the size distributions shown in figure 5, indicate that Ames 24E2 coating can shed two kinds of particles. The $200 \mu \mathrm{m}$ or larger size mode is composed of SiC grit covered by black pigmented paint and adhesive resin. The $25-70 \mu \mathrm{m}$ size particles are clumps of black pigmented adhesive resin. This is quite consistent with the composition of the coating. 
2. Comparison of tables 2 and 3 with table 4 indicates that brushing with the acid brush or rubbing with a finger knocks off more of each size particle than does vibrational cryogenic temperature.

3. The shedding of large particles by this particular baffle assembly was significantly reduced on the fifth run when the manner in which the sharp, inner edge of the baffle vane was coated was changed by using only Ames 24E2M on it. The adhesion of large particles is obviously better when they do not protrude from the narrow edge of a vane.

4. Table 4 shows that particle shedding does not continue on the repeated runs (\#2 and \#4), i.e., after the initial installation of the assembly. Thus the shedding which does occur is associated with the initial application of the coating and not with a continuing failure of the coating due to cryogenic vibration.

5. The random vibration mode used on the 4th run does not appear any more severe than the sinusoidal vibrations used on the other runs.

6. Comparison of the 1 st and 5 th runs in table 4 indicates that the coating can be applied to the intersection of a baffle vane and telescope tube after assembly if the vane is similar to those used

Table 4. Cryo-vibration particle count (particles/meter ${ }^{2}$ ) [background contamination has been subtracted out]

\begin{tabular}{|c|c|c|c|c|c|}
\hline \multirow[b]{2}{*}{$\begin{array}{l}\text { Run } \\
\text { (File\#) }\end{array}$} & \multicolumn{4}{|c|}{ Size Ranges } & \multirow[b]{2}{*}{ Description } \\
\hline & $\geq 200 \mu$ & $70 \rightarrow 25 \mu$ & $25 \rightarrow 14 \mu$ & $<14 \mu$ & \\
\hline $1(173)$ & 180 & 60 & 60 & $\sim 150$ & $\begin{array}{l}\text { Vane-Tube intersection is uncoated. Edge of } \\
\text { baffle vane was coated. Grits are suspended out } \\
\text { from edge of vane. } \\
\text { Installation contamination (1st shake). }\end{array}$ \\
\hline $2(174)$ & - & - & - & $-\overline{150}$ & $\begin{array}{l}\text { Repeat run (only changed petri dish). } \\
\text { Residual contamination (2nd shake). }\end{array}$ \\
\hline $3(176)$ & - & - & $\begin{array}{c}60 \\
240\end{array}$ & - & $\begin{array}{l}\text { Vane-tube intersection freshly coated. } \\
\text { Installation contamination (3rd shake). }\end{array}$ \\
\hline $4(177)$ & - & - & - & - & $\begin{array}{l}\text { Repeat run (only changed petri dish). Used } \\
\text { random vibration PSD curve for SIRTF. } \\
\text { Residual contamination (4th shake). }\end{array}$ \\
\hline $5(180)$ & 30 & 90 & 30 & - & $\begin{array}{l}\text { Completely coated a new, fully assembled Baffle } \\
\text { Vane Assembly. No large particles on edge of } \\
\text { baffle vane. Used Ames 24E2M on edge of vane. } \\
\text { Installation contamination (1st shake). }\end{array}$ \\
\hline
\end{tabular}


here, where the distance between securing screws is less than $21 \mathrm{~cm}$. That is, the coating can withstand whatever motion exists between the outer edge of the vane and the tube wall for this realm of vane dimensions.

\section{CONCLUSION}

Ames 24E2 has been shown to be a low outgassing coating that on a macroscopic basis adheres well to aluminum at both ambient and cryogenic temperatures. Macroscopically it easily passes the Tape Test, Acid Brush Test, tensile strain to $>4 \mathrm{E}-3$ at $\sim 90^{\circ} \mathrm{K}$, thermal cycling from $315^{\circ} \mathrm{K}$ down to $4^{\circ} \mathrm{K}$, and sinusoidal acceleration to $45 \mathrm{G}$ 's at $90^{\circ} \mathrm{K}$. On a microscopic basis, some loose particles were found associated with several of the tests (thermal cycling, acid brush, simple acceleration in liquid helium, and cryo-vibration of the baffle assembly). Their presence was also noted at room temperature (during trials prior to simple acceleration in liquid helium), which indicates that they are not generated by a reaction to the low cryogenic temperatures. In fact several runs were made at liquid nitrogen temperature where no particles at all were found. It is thus concluded that a few weaklybound particles probably exist on the surface of the coating immediately after application. A lower bound on the number of such particles may be given by run $\# 5$ of the cryo-vibration test $\left(\sim 30 / \mathrm{m}^{2}\right.$ in the large size mode and $\sim 75 / \mathrm{m}^{2}$ in the small mode). If these numbers are a matter of serious concern, then a simple remedy might be to lightly tap or vibrate the coated surface to jar the particles loose before use. Perhaps this could be accompanied by air pressure, $\mathrm{CO}_{2}$ jet flush and/or vacuum.

\section{REFERENCES}

1. Smith, S. M.: Reflectance of Ames 24E, Infrablack, and Martin Black. In Stray Light and Contamination in Optical Systems, R. Breault, ed., Proc. SPIE 967, 1988, pp. 248-254.

2. Smith, S. M.: Formulation of Ames 24E2 IR-Black Coating. NASA TM-102864, March 1991.

3. Campbell, W. A., Jr.; and Marriott, R. S.: Outgassing Data for Selecting Spacecraft Materials. NASA Reference Publication 1124 Revised, 1987, p. 86.

4. Houck, J. R.: New Black Paint for Cryogenic IR Applications. In Scattering in Optical Materials, S. Musikant, ed., Proc. SPIE 362, 1982, fig. 1, p. 54.

NOTE: The ASTM tests and practices mentioned in this report can be found in the Annual Book of ASTM Standards published by the American Society for Testing and Materials, 1916 Race St., Philadelphia, PA 19103. 


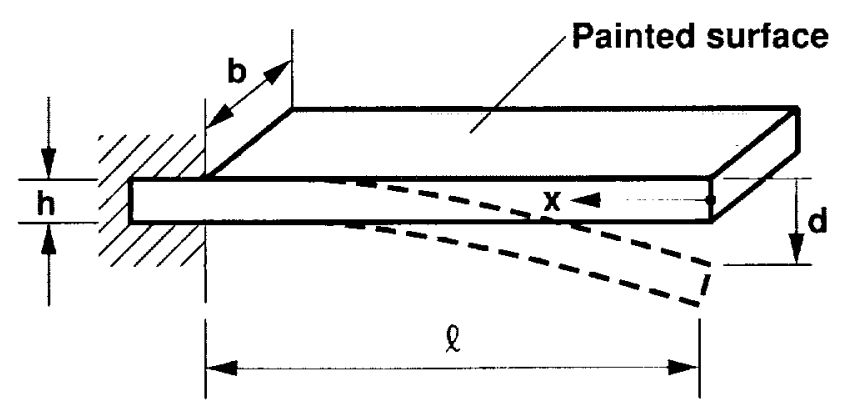

Figure i. Cantilever beam parameters.

\section{ORIGINAL PAGE \\ BLACK AND WHITE PHOTOGRAHH}

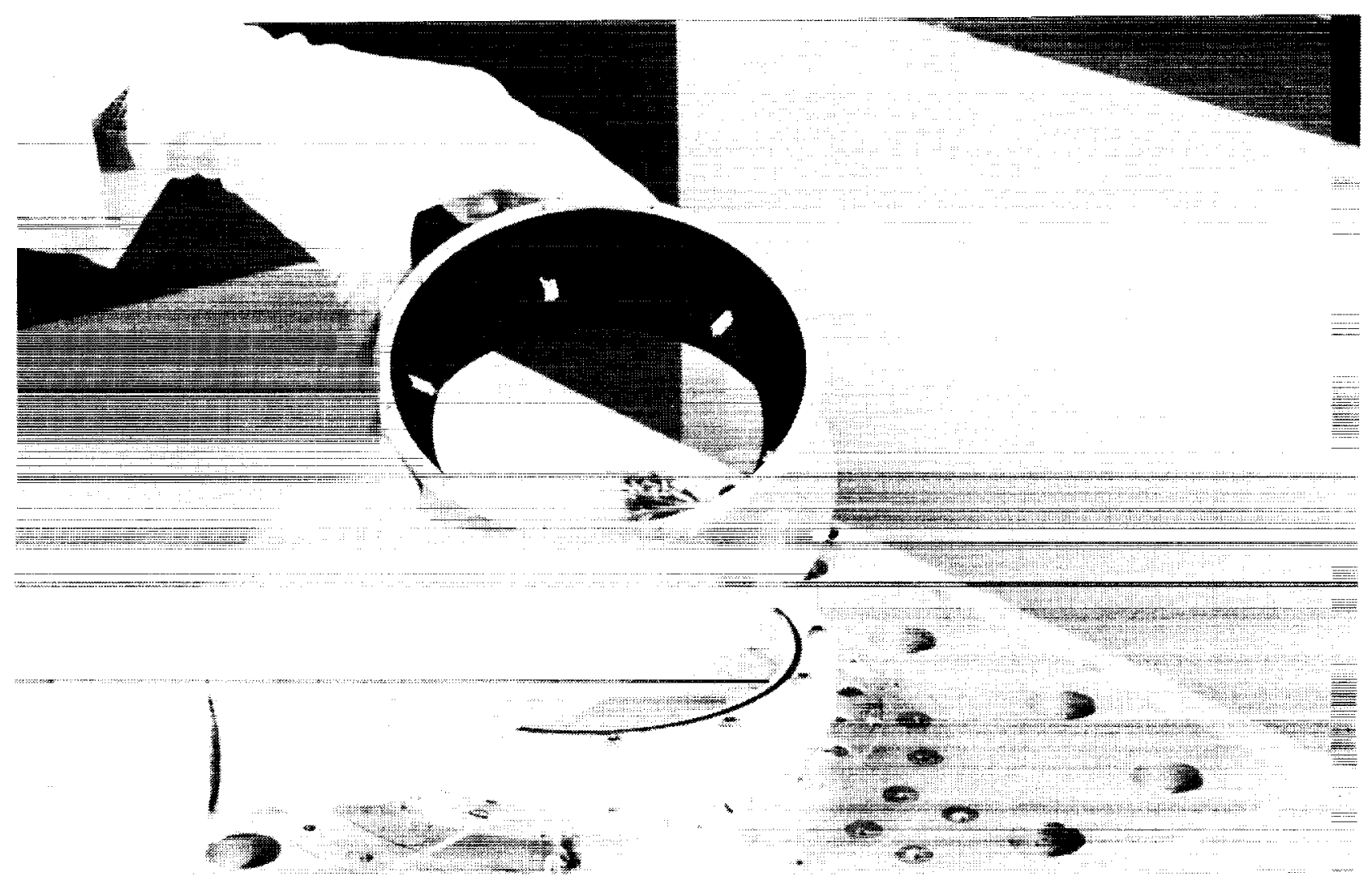

Figure 2. Baffle vane assembly being mounted in the nitrogen-cooled adaptor. The three white areas on the vane are epoxy plugs over screws through the telescope tube. 


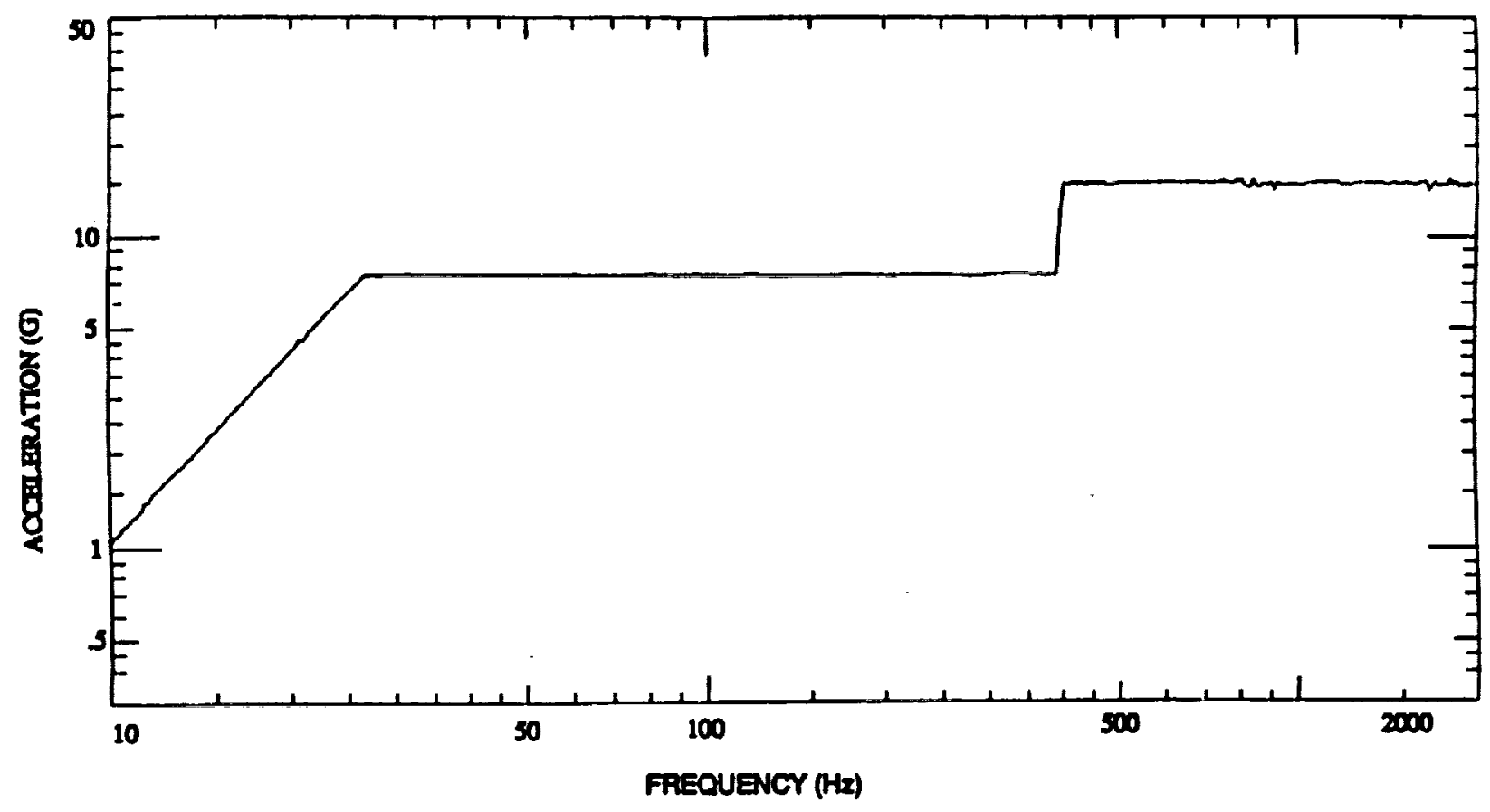

Figure 3. Sinusoidal oscillation spectrum (run \#176).

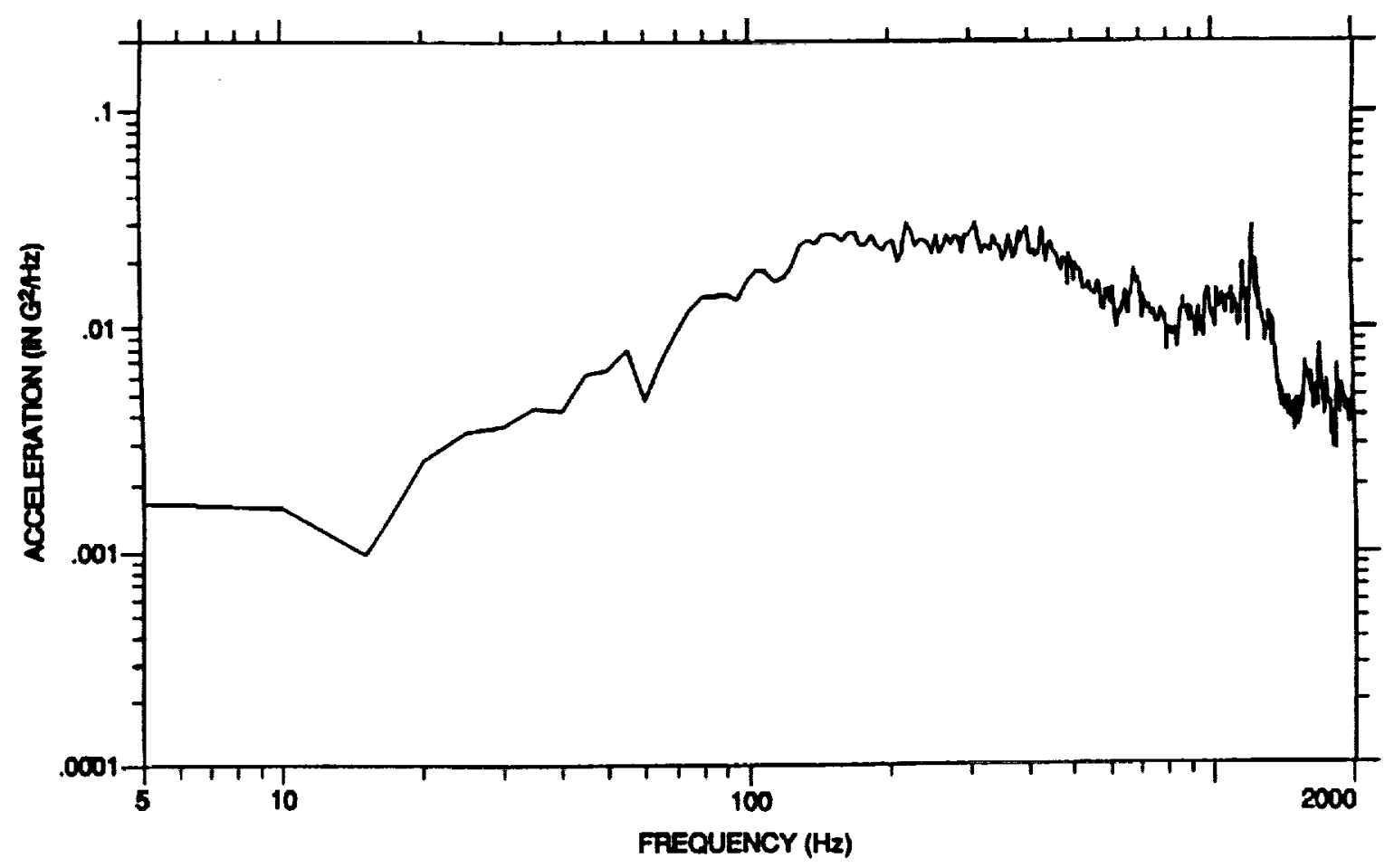

Figure 4. Random oscillation spectrum (run \#177). The rms acceleration over the frequency range was $4.918 \mathrm{G}$. 


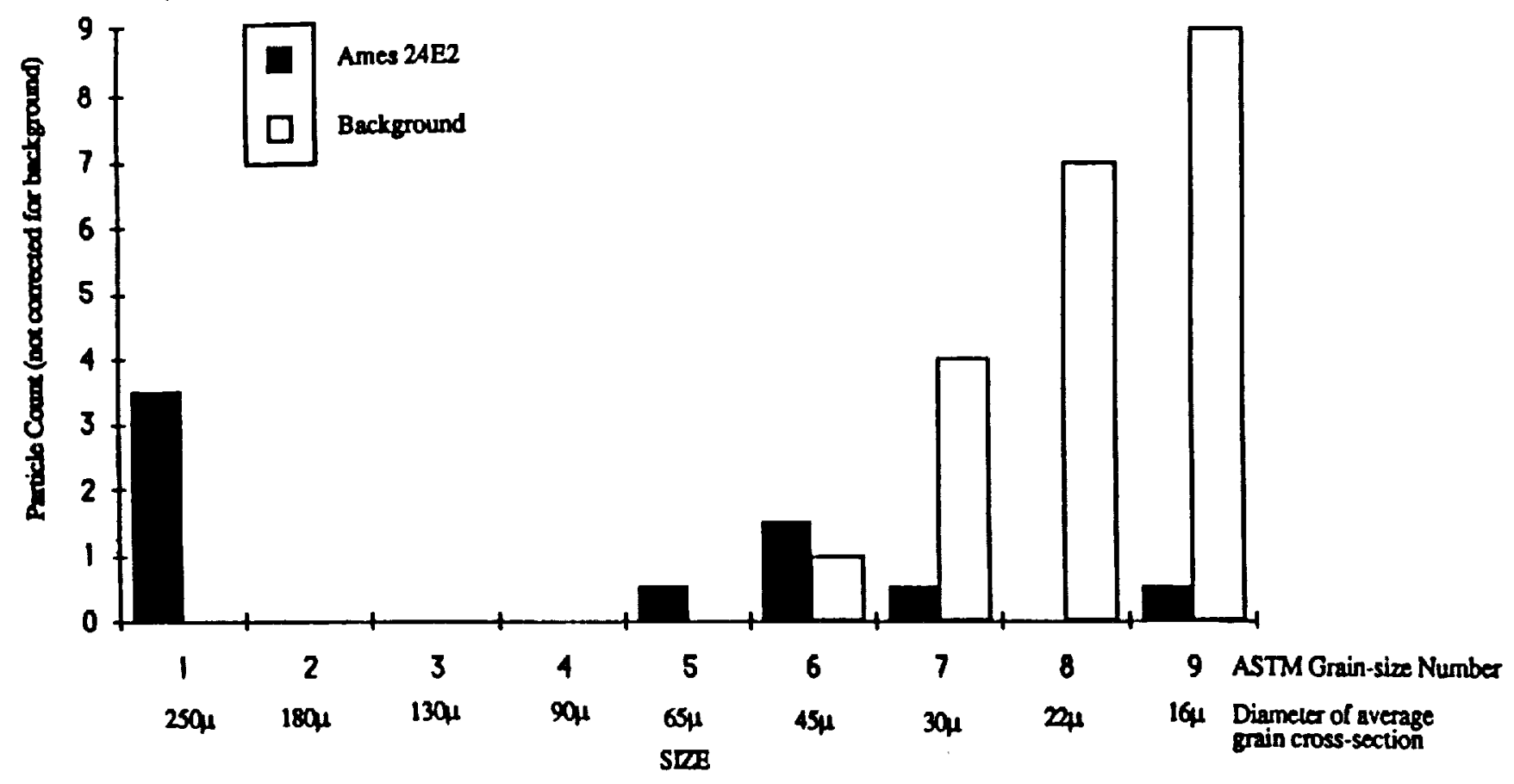

Figure 5. Average particle counts.

\author{
ORIGINAL PAGE \\ BLACK AND WHITE PHOTOGRAPH
}
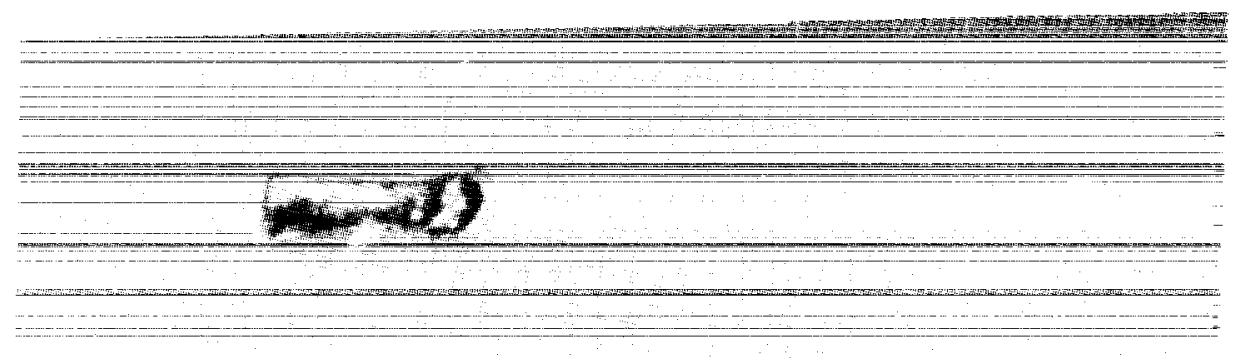

Figure 6. A small particle $(\sim 45 \mathrm{~m}$ long) of Ames $24 \mathrm{E} 2$. Bright white spots are easily identified background contamination particles (not all background particles were bright, however). 


\begin{tabular}{|c|c|c|c|c|}
\hline N/NSA & \multicolumn{4}{|c|}{ Report Documentation Page } \\
\hline $\begin{array}{l}\text { 1. Report No. } \\
\text { NASA TM-102863 }\end{array}$ & \multicolumn{2}{|c|}{ 2. Government Accession No. } & \multicolumn{2}{|c|}{ 3. Recipient's Catalog No. } \\
\hline \multirow{2}{*}{\multicolumn{3}{|c|}{$\begin{array}{l}\text { 4. Tite and Subtitle } \\
\text { Cryo-Mechanical Tests of Ames 24E2 IR-Black Coating }\end{array}$}} & \multicolumn{2}{|l|}{$\begin{array}{l}\text { 5. Report Dale } \\
\text { June } 1991\end{array}$} \\
\hline & & & \multicolumn{2}{|c|}{ 6. Performing Organization Code } \\
\hline \multirow[t]{2}{*}{$\begin{array}{l}\text { 7. Author(s) } \\
\text { Sheldon M. Smith }\end{array}$} & & & \multicolumn{2}{|c|}{$\begin{array}{l}\text { 8. Performing Organization Report No. } \\
\text { A-90279 }\end{array}$} \\
\hline & & & \multicolumn{2}{|l|}{$\begin{array}{r}\text { 10. Work Unit No. } \\
188-78-44\end{array}$} \\
\hline \multicolumn{3}{|c|}{ 9. Performing Organization Name and Address } & \\
\hline \multicolumn{3}{|c|}{$\begin{array}{l}\text { Ames Research Center } \\
\text { Moffett Field, CA } 94035-1000\end{array}$} & \multicolumn{2}{|c|}{ 11. Contract or Grant No. } \\
\hline \multirow{2}{*}{\multicolumn{3}{|c|}{$\begin{array}{l}\text { 12. Sponsoring Agency Name and Address } \\
\text { National Aeronautics and Space Administration } \\
\text { Washington, DC 20546-0001 }\end{array}$}} & \multicolumn{2}{|c|}{$\begin{array}{l}\text { 13. Type of Report and Period Covered } \\
\text { Technical Memorandum }\end{array}$} \\
\hline & & & \multicolumn{2}{|c|}{\begin{tabular}{|l} 
14. Sponsoring Agency Code \\
\end{tabular}} \\
\hline \multicolumn{5}{|c|}{$\begin{array}{ll}\text { Point of Contact: } & \text { Sheldon M. Smith, Ames Research Center, MS 244-10, } \\
& \text { Moffett Field, CA } 94035-1000,(415) \text { 604-3533 or FTS 464-3533 }\end{array}$} \\
\hline \multicolumn{5}{|c|}{$\begin{array}{l}\text { 16. Abstract } \\
\text { In addition to the ambient condition "tape test," five mechanical tests of the IR-black coating, Ames } \\
\text { 24E2, have been performed at either liquid helium or liquid nitrogen temperature. Tensile strain in the } \\
\text { coating at liquid nitrogen temperature has been measured up to values of } 4 \mathrm{E}-3 \text {, both before and after the } \\
\text { coating was cycled down to liquid helium temperature. When applied to an aluminum substrate which was } \\
\text { then bent in liquid nitrogen, the aluminum substrate always failed (permanently deformed) well before the } \\
\text { coating failed. Sinusoidal accelerations up to } 45 \mathrm{Gs} \text { in liquid nitrogen and } 25 \mathrm{Gs} \text { in liquid helium did not } \\
\text { crack or otherwise visibly damage the coating. Both sinusoidal and random acceleration at about } 90^{\circ} \mathrm{K} \text { of } \\
\text { a representative baffle vane structure, at frequencies from } 10 \text { to } 2,000 \mathrm{~Hz} \text { and up to } 15 \mathrm{Gs,} \mathrm{did} \mathrm{not} \mathrm{damage} \\
\text { the coating, even at the intersection of a baffle with the telescope tube. Thus on a macroscopic level, } \\
\text { cryogenic cooling and various levels of acceleration and strain did not affect this coating. However, on a } \\
\text { microscopic scale some loose particles were found associated with several tests. Since they were also noted } \\
\text { during room temperature trials, it is concluded that a few weakly bound particles probably exist on the } \\
\text { coating surface immediately after application. A lower bound of about } 30 \text { large, and } 75 \text { small particles per } \\
\text { square meter is established. Outgassing data are also given. }\end{array}$} \\
\hline \multicolumn{2}{|c|}{$\begin{array}{l}\text { 17. Key Words (Suggested by Author(s)) } \\
\text { IR-black coatings, Fav-IR telescopes, Space } \\
\text { telescopes, Vibration, Adhesion, Cryogenics, } \\
\text { Strain, Strain measurement }\end{array}$} & \multicolumn{3}{|c|}{$\begin{array}{l}\text { 18. Distribution Statement } \\
\text { Unclassified-Unlimited } \\
\text { Subject Category - } 88\end{array}$} \\
\hline $\begin{array}{l}\text { 19. Security Classif. (of this report) } \\
\text { Unclassified }\end{array}$ & $\begin{array}{l}\text { 20. Socurity Cla } \\
\text { Unclassi }\end{array}$ & $\begin{array}{l}\text { I page) } \\
\text { (n) }\end{array}$ & $\begin{array}{c}\text { 21. No. of Pages } \\
16\end{array}$ & $\begin{array}{r}\text { 22. Price } \\
\mathrm{A} 02\end{array}$ \\
\hline
\end{tabular}

